\title{
V20 - SELECIONANDO A ROLHA MAIS ADEQUADA PARA NOSSOS PRODUTOS IMUNOBIOLÓGICOS
}

\author{
Celso de Farias Crespo ${ }^{1}$, Isabella Manjud Maluf ${ }^{1}$ e Sérgio Luiz de Lima Assumpção ${ }^{1}$
}

1. Bio-Manguinhos, Fiocruz, Rio de Janeiro, Brasil.

Objetivo: Bio-Manguinhos vem realizando uma série de experimentos para avaliar a performance de diferentes tipos de rolhas na liofilização e estabilidade da vacina Hib. O objetivo desses experimentos é respaldar, por meio de base científica sólida, a escolha da rolha mais adequada ao processamento de imunobiológicos liofilizados, melhorando a qualidade de sua produção.

Metodologia: Foram estabelecidas metodologias para estudar os seguintes parâmetros:

. Nível de umidade adicionado às rolhas devido ao processo de esterilização a vapor, determinado a partir das perdas percentuais de umidade das rolhas antes e após a esterilização;

. Nível de umidade adicionado às rolhas devido ao processo de liofilização, determinado a partir das perdas percentuais de umidade das rolhas antes e após a liofilização;

. Estabilidade em tempo real (em andamento), acelerada e crítica - evolução da umidade residual do liófilo de vacina de lotes processados com diferentes tipos de rolhas - em função das condições de estocagem: temperatura de 2 a $8^{\circ} \mathrm{C}$ por 4 anos, $25^{\circ} \mathrm{C}$ por 6 meses, $40^{\circ} \mathrm{C}$ e $51^{\circ} \mathrm{C}$, ambas por 48 horas;

. Operacionalidade industrial - simulação comercial.

A umidade adicionada às rolhas devida aos processos de esterilização e de liofilização foi determinada por termogravimetria, a $105^{\circ} \mathrm{C}$ por $48 \mathrm{~h}$. Os lotes experimentais processados com diferentes tipos de rolhas foram produzidos em liofilizador piloto Lyoflex 1.0 Edwards. A umidade residual desses lotes, estocados às temperaturas de $25^{\circ} \mathrm{C}, 40^{\circ} \mathrm{C}$ e $51^{\circ} \mathrm{C}$, foi determinada por titulação coulométrica. Para o tratamento de dados e simulações computacionais utilizou-se Origin 8.6 Pro.

Resultado: A aplicação das metodologias revelou diferenças significativas de performance, seja das rolhas individualmente, seja de parâmetros de qualidade dos lotes de vacina Hib processados com diversos tipos de rolhas. As metodologias foram 
adequadas para classificar as rolhas segundo o nível de umidade adicionado devido aos processos de esterilização e de liofilização e também para classificar qualitativamente os diversos lotes de vacina quanto à evolução da umidade residual em função das condições de estocagem. Além disso, foi possível avaliar os tipos de rolhas que se mostram viáveis de serem operadas nos equipamento da produção comercial.

Conclusão: Esse trabalho avaliou rolhas de diversos designs e fornecedores. A seleção da rolha mais adequada a um produto envolve avaliação de aspectos logísticos, de Produção e, sobretudo, aspectos da qualidade do produto, que são expressos através da estabilidade ao longo do tempo. Para Bio-Manguinhos, produtor de vacinas liofilizadas que precisam ser estáveis por longos períodos, interessa a rolha que, ao longo do tempo, libera a menor quantidade de umidade para o produto. Nesse trabalho, metodologias científicas foram estabelecidas para apontar as rolhas com essas características e assim, colaborar com as iniciativas internas que buscam constantemente a melhoria da qualidade dos produtos fornecidos por Bio-Manguinhos. 